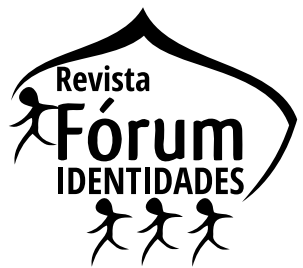

\title{
IDENTIDADE INTERCULTURAL E AS POSSIBILIDADES DE APRENDIZAGEM EDUCACIONAL DIALÓGICA'
}

\section{THE INTERCULTURAL IDENTITY AND THE POSSIBILITIES OF DIALOGICAL EDUCATIONAL LEARNING}

\author{
Marciele Nazaré Coelho
}

\begin{abstract}
Resumo: O presente artigo tem como foco de análise as múltiplas aprendizagens em contextos educativos, considerando os aportes da interculturalidade e da identidade intercultural como possibilidade para o diálogo entre e no interior das diferentes culturas, etnias e povos. A partir das vivências de crianças angolanas, identificamos os fatores transformadores e os fatores excludentes para um processo educativo à favor da diversidade cultural, racial, étnica, de modos de viver, pensar e a constituição das identidades livres e plurais, dentro do quadro de referência da metodologia comunicativa. A perspectiva intercultural se coloca como uma saída dentro das perspectivas duais, proporcionando aprendizagens, diálogos, vivências e ações mais dialógicas entre as crianças angolanas de diferentes etnias e fornece subsídios para uma educação intercultural na escola brasileira.
\end{abstract}

Palavras-chave: Identidade. Interculturalidade. Igualdade de diferenças. Aprendizagens. Angola.

\begin{abstract}
The present article analises multiples learning and educative context, considering the contributions of interculturality and intercultural identity as a possibility for dialogue between and within different cultures, ethnicities and peoples. From the experiences of Angolan children, we identified the transforming factors and the exclusive factors for an educational process in favor of cultural, racial and ethnic diversity, the ways of living, thinking and the constitution of free and plural identities within the frame of reference of the communicative methodology. The intercultural perspective is seen as an outlet within dual perspectives, providing learning, dialogues, experiences and more dialogical actions among Angolan children of different ethnicities and providing subsidies for an intercultural education in the Brazilian school.
\end{abstract}

Keywords: Identity. Interculturality. Equality of diferences. Learning. Angola.

\footnotetext{
${ }^{1}$ Artigo recebido em 14 de novembro de 2020 e aceito em 15 de fevereiro de 2021

2 Professora Associada no Instituto Superior de Ciências Sociais e Relações Internacionais (CIS - Angola) e Pesquisadora do Centro de Estudos Africanos (CEACIS). Pedagoga e Mestre em Educação pela Universidade Estadual de Campinas (UNICAMP), Doutora em Educação pela Universidade Federal de São Carlos (UFSCar). E-mail: marcielecoelho@yahoo.com.br. ORCID: https://orcid.org/0000-0002-9241-9268.
} 


\section{Introdução}

O presente artigo traz à discussão as possibilidades de aprendizagens em diferentes contextos educativos, a partir da abordagem intercultural, dialógica de construção de identidades, vivências e experiência culturais, étnicas e de diversidade.

O conceito de interculturalidade será aqui aprofundado como possibilidade de mudança e transformação em processos de aprendizagens, considerando as dificuldades vividas no âmbito da construção de uma identidade que chamaremos aqui de uma identidade livre e plural para todas as crianças, a identidade intercultural.

Neste âmbito, abordaremos as possibilidades de aprendizagens, no âmbito da educação intercultural, dialógica e de construção da identidade intercultural, em diferentes contextos educacionais, a partir da identificação de fatores transformadores e excludentes. Como objetivo geral buscamos analisar a construção da identidade intercultural dentro da perspectiva dialógica e dos estudos indígenas, trazendo uma reflexão sobre as possibilidades de transformação das aprendizagens das crianças em espaços escolares ou não, a partir de experiências no Projeto de Leitura e Escrita, uma iniciativa não-governamental, realizado com crianças de 6 à 12 anos, em Angola, na Capital Luanda.

No âmbito específico, buscamos perceber o contexto histórico do surgimento do conceito de educação intercultural, dialógica e a construção do conceito de identidade intercultural; identificar as possibilidades da identidade intercultural para a construção de uma educação mais plural e diversa em diferentes contextos escolares ou não e, destacar, a partir de vivências de crianças angolanas, os fatores transformadores e os fatores excludentes para um processo educativo à favor da diversidade cultural, racial, étnica, de modos de viver e pensar e a constituição positiva, diversa e dialógica das identidades.

Metodologicamente, o estudo apoia-se na perspectiva da metodologia comunicativa, que busca dentro das vivências e construções de saberes identificar os fatores excludentes, mas também os fatores transformadores que possibilitam a mudança social e educativa.

\section{A interculturalidade como possibilidade de uma educação mais plural, diversa e dialógica}

Nas últimas décadas do século XX e princípio do século XXI, as preocupações com os conceitos de identidade, diversidade, diferença, multiculturalidade, interculturalidade, estiveram presentes em diferentes contextos, históricos, políticos, educacionais, sendo preocupações de algumas políticas públicas e de ações de garantia de direitos e de justiça social. 
Segundo Mello, Braga e Gabassa (2012), a defesa da igualdade de direitos, de vivência da cidadania de forma plena para todas as pessoas, especialmente para as que tem tido menos acesso aos seus direitos, tem representado um desafios em diferentes contextos sociais, mas também, uma construção necessária para que possamos ter sociedades mais justas, democráticas e livres.

Neste contexto, por um lado, existe a emergência dessa preocupação nos contextos educacionais, por outro, na contramão, as realidades que necessitam de transformação educativa na busca por uma educação mais plural, diversa e igualitária. O surgimento do conceito de interculturalidade no seio das preocupações educacionais se coloca como uma possibilidade de transformação dos espaços educativos.

Nesta perspectiva, partimos dos estudos da educação intercultural para os povos indígenas (MOYA, 2009; MOYA, LÓPEZ e VALIENTE, 1999) em diálogo com os estudos das Teorias Dialógicas (ELBOJ et al., 2002), que, segundo Coelho (2011), nos finais dos anos de 1990 e início de 2000 apresentam intensas preocupações provindas dos países europeus acerca da diversidade na escola, dos movimentos migratórios e do acirramento do processo de globalização que aproxima o global e o local. Tal perspectiva oferece subsídios para a educação dialógica.

O conceito de interculturalidade, aprendizagem na perspectiva dialógica e a preocupação com a diversidade podem ser encontrados a partir de estudos realizados em diferentes países, pelo que, destacaremos dois contextos, a saber: as vertentes interculturais construídas na América Latina, incluindo os estudos no Brasil e, os estudos nos países europeus, acerca da educação dialógica dentro das perspectivas duais, especificamente na Espanha.

A história da construção do conceito de interculturalidade pauta-se, na América Latina, por estudos que nascem no interior das preocupações com a interculturalidade e com a educação bilíngüe, dentro da escola indígena (PAULA, 1999). Neste contexto ganham destaque as políticas educacionais voltadas para os estudos indígenas e a escola indígena propriamente dita.

Segundo Moya, López e Valiente (1999), na América Latina há uma ampla experiência do Estado e de instituições privadas em projetos e programas de educação bilíngue e intercultural para os povos indígenas da região. Esta preocupação surge a partir da década de 1980, promovendo políticas educacionais e ações em prol do desenvolvimento dessa modalidade de educação. Muitas dessas políticas foram impulsionadas pelos movimentos sociais e movimentos étnicos que pressionaram o Estado para que pudessem ter uma participação ativa no seu planejamento. 
As políticas educacionais e as políticas sociais relativas aos povos indígenas podem ser encontradas, especialmente, em países como Colômbia, Peru, Brasil, Guatemala, Equador, Bolívia e México. Embora, tais países tenham variações quanto ao número da população indígena, em todos há destaques de políticas públicas relativas à temática, o que não significa que os níveis de participação e de benefícios as referidas comunidades estejam totalmente contempladas.

A educação indígena voltada para a biculturalidade foi o primeiro viés desse ensino.

Conforme afirma Moya (1998), citada por Coelho (2011), o conceito de biculturalidade é um conceito que antecede o de interculturalidade no âmbito dos processos educativos.

(...) A biculturalidade e o bilinguismo foram implementados nas primeiras etapas da educação bilíngue assimilacionista, partindo do pressuposto de que, se era possível adquirir dois sistemas linguísticos, era igualmente possível adquirir dois sistemas culturais. Entendia-se que, (...) passar-se-ia da cultura própria para uma "cultura maior", a partir da aprendizagem da língua (MOYA, 1998 apud COELHO, 2011, p. 55).

Assim, o conceito de biculturalidade apresentava um hiato que não resolvia as questões de interação dialética entre as culturas e as línguas, colocando em questão a existência de uma educação pautada na biculturalidade e no bilinguísmo, outrora defendidos.

Os estudos teóricos iniciam uma caminhada no sentido de uma educação indígena que fosse intercultural e bilíngüe ao mesmo tempo.

O binômio intercultural e bilíngüe é considerado como constitutivo da categoria "escola indígena". Essa preocupação em afirmar os currículos educacionais indígenas como interculturais nasce de uma situação já existente de fato. Ou seja, antes de a escola ser intercultural, as sociedades indígenas já estão se relacionando com a sociedade não-indígena, desde o momento do contato. E o modo como ocorrem essas relações se reflete no cotidiano da escola. Não é outra a razão de só recentemente esse adjetivo aparecer qualificando a escola indígena, coincidindo com a época em que o modelo de educação integradora, implantado desde o início da colonização em nosso país, começou a ser questionado pelas comunidades indígenas e seus aliados (...). (PAULA, 1999, p. 77).

É neste cenário que surgem questionamentos sobre tais percepções, fortalecendo o desejo pela busca de uma compreensão das culturas e línguas que priorizasse o diálogo entre elas, essencialmente no contexto educativo.

Assim, nasce a interculturalidade, nos finais do século XX, no interior dos Estudos Indígenas, no âmbito das políticas públicas, dos movimentos sociais e no contexto educacional, desenvolvendo-se a partir dos conceitos de assimilação 
cultural, biculturalidade, bilinguismo e pluralidade. A Interculturalidade avança em relação à tais conceitos, pois, pressupõe o diálogo, a interação cultural e de saberes dentro de uma convivência respeitosa.

Segundo Lima Constantino e Coelho (2020), citando Ruiz (2014), o conceito de interculturalidade é polissêmico. O conceito desenvolveu-se a partir do reconhecimento do conceito de multiculturalidade, em que se reconhece a diversidade humana, a partir de duas perspectivas, a da interculturalidade funcional e a da interculturalidade crítica. A interculturalidade funcional, também entendida como neoliberal, afirma a necessidade de diálogo e de reconhecimento, no entanto, não aborda as desigualdades sociais, econômicas e de direitos dos povos desprestigiados socialmente. No caso da interculturalidade crítica, o destaque recai sobre às etnias e culturas, priorizando a sua valorização, sua manutenção e, ao mesmo tempo, há espaço para o olhar crítico, no que tange a construção identitária e cultural, como algo que não é imutável, com o foco nas desigualdades de classe, econômicas, de direitos e de justiça social, desconsideradas na vertente destacada anteriormente.

A polissemia do conceito de interculturalidade se expande por toda América Latina, trazendo diferentes aportes para a sua compreensão, desde o seu entendimento mais tradicional, passando pelas teorias de contraponto ao colonialismo em alguns países latinos, até as perspectivas que apontam a necessidade de reconstrução do conceito pensando também a sua metodologia dentro do quadro das investigações científicas e sua atuação em contextos que ultrapassem o educacional (MOYA, 1999; LÓPEZ, 1999).

Marín (2017) ressalta que, com o surgimento do conceito de interculturalidade, na América Latina, os governos a utilizaram como possibilidade de ação à favor da assimilação cultural dos povos indígenas, no entanto, a visão intercultural tem suas raízes no diálogo e na interação entre culturas e saberes, o que possibilita, na verdade, a convivência respeitosa entre todos e todas.

Assim, a interculturalidade é entendida como princípio da educação nos países multiétnicos, e assim em todos os países que se encontram dentro dos processos de globalização, apontando para um desenvolvimento de sociedade não apenas multiétnicas e pluriculturais, mas, acima de tudo, intercultural nos seus princípios de participação e de respeito mútuo com o foco da unidade na diversidade (SPEISER, 1999).

O conceito de unidade na diversidade e de diálogo de Freire (2006) contribuem na composição dos conceitos apresentados. A unidade na diversidade pressupõe a convivência de diferentes culturas em um mesmo espaço, fundamentada no respeito às diferenças e na convivência e ação democrática e dialógica, neste sentido, temos o diálogo como possibilitador dessa convivência. 
No âmbito das teorias dialógicas e da educação dialógica a unidade na diversidade e a igualdade de diferenças se colocam como conceitos centrais que olham para uma outra perspectiva, indo além da interculturalidade e seu reconhecimento, na medida em o diálogo apoia-se na possibilidade de transformação de diferentes contextos educativos de forma dialógica.

A igualdade de diferenças faz parte dos princípios das aprendizagens dialógicas desenvolvidas pela Comunidade de Pesquisa de Excelência para Todos (CREA), da Universidade de Barcelona e trabalhado no contexto brasileiro pelo Núcleo de Investigação e Ação Social e Educativa (NIASE), na Universidade Federal de São Carlos (UFSCar) que foi no Brasil. (MELLO, BRAGA e GABASSA, 2012).

O conceito de aprendizagem dialógica assenta na educação que tenha por objetivos a igualdade, a solidariedade, a aprendizagem instrumental e a transformação (FLECHA e TORTAJADA, 2000).

O conceito de Igualdade de diferenças compõe os sete princípios de uma educação para a máxima aprendizagem dos alunos, concebido como princípios da aprendizagem dialógica em que faz parte o diálogo igualitário, a inteligência cultural, a transformação, dimensão instrumental, a criação de sentido, a solidariedade. A igualdade de diderenças preeupõe o igual direito de ser diferente (ELBOJ et. al, 2002; AUBERT, GARCIA e RACIONERO, 2009).

As referidas concepções entendem que a diversidade é fundamental para todas as sociedades, todas as escolas e todos os processos educativos. A diferença é parte da diversidade e deve ser compreendida como ponto de partida para o diálogo na diversidade e no seu interior.

A proximidade existente entre os povos, sejam culturais, linguísticas ou de traços de sua tradição são elementos importantes para analisarmos a construção plural e dinâmica das identidades, das culturas e da relação entre elas, que intitula-se, interculturalidade.

Consideramos que estar entre as culturas e dialogando com elas é o que define uma educação intercultural e dialógica e para que ela seja justa, fraterna e que caminhe buscando atingir os melhores objetivos educacionais para todas as crianças trazemos o conceito de igualdade de diferenças.

A educação intercultural e dialógica valoriza a igualdade de diferenças e assenta-se no ato que consideramos mais importante no processo educativo, o diálogo, pois, não é possível aprender sem dialogar.

Para Freire (1987), o diálogo é o que possibilita que o "eu" se reconheça nos "outros eu", possibilita a ação, a crítica e a transformação.

A vivência entre as culturas, em diálogo, pressupõe um diálogo que vai além do reconhecimento, da identificação de situações de não diálogo, de não-fazer, busca construir relações entre os sujeitos baseada na igualdade de diferen- 
ças, respeitando e possibilitando ao sujeito o igual direito de viver as diferenças, sejam elas culturais, econômicas, sociais, étnicas, raciais, de gênero ou outras.

\section{Caminhos para a construção do conceito de identidade intercultural: os aportes da interculturalidade e da igualdade de diferenças}

O reconhecimento de si, enquanto parte de um grupo, de uma cultura e a constituição de suas identidades se faz no diálogo intersubjetivo, na relação e nas vivências dos sujeitos.

Todo sujeito quer se sentir parte do grupo, quer ter sua cor de pele, cabelo, cultura, traços físicos valorizados pelo Outro e quando essa ação não acontece, as situações de baixa estima, as dificuldades de inserção, de permanência na escola, tornam-se evidentes.

Nesse sentido, todas as pessoas têm o direito de viver plenamente a sua cultura, as suas identidades, formas de vida, de pensar e se relacionar, sendo este direito, pautado na compreensão ampla da igualdade (BOTTON, 2004).

A identificação por uma cultura, por um modo de ser, de estar, de pensar será resultado das relações e inter-relações que vão sendo tecidas na teia que o cotidiano proporciona, a partir do contato com os outros sujeitos, constituindo assim a sua identidade.

A percepção da identidade ela é relacional, o diálogo entre o "nós" e os "outros" definem o eu, ou seja, nenhum grupo ou pessoa tem uma identidade em sua essência, os grupos se identificam com certos modos de ser, estar e viver, em contextos históricos específicos e a partir das relações sociais que estabelecem (GRIMSON, 2001).

A aproximação de culturas faz com que as questões de diversidade se tornem vivas em vários momentos educacionais e, neste sentido, conforme afirma Botton (2004), a relação com o outro está no centro do processo da identidade pessoal e no centro das relações interculturais.

Assim, o ponto fulcral nessa discussão é a visão que temos do Outro, o olhar para a diversidade em uma visão de igualdade.

No caso brasileiro, nos deparamos com uma realidade que vê a diversidade étnica, racial e cultural em desvantagem diante das culturas entendidas, historicamente, como hegemônicas.

Estar em diferentes posições sociais, econômicas, manter as línguas africanas ou indígenas, as religiões, tradições e culinária, não tem sido a realidade vivenciada pela população negra brasileira.

A constituição identitária nas instituições educativas brasileiras é repleta de descaminhos quando ser negro é entendido como pertencente a uma cultura com traços, modos de ser que são considerados como desiguais e de menor valor. 
Posto que a cultura é uma das ancoragens que nos situa no mundo e nos faz criar sentido a ele (WHITAKER, 2003 apud COELHO, CONSTANTINO e MOREIRA, 2012), o acolhimento das diversidades torna-se elemento essencial para o contexto educativo, seja no contexto brasileiro ou não.

Aqui se coloca a questão da valorização da diversidade e ao mesmo tempo da unidade. De acordo com Wieviorka (1997), citado por Pleyers (2004), a questão está em combinar a própria identidade com a sua vertente mais geral.

Para Mello, Braga e Gabassa (2012), toda a diversidade existente, e no caso específico, da escola, deve tornar-se fonte de conhecimento e de riqueza.

As questões relativas a identidade religiosa, a crença por determinados princípios, a forma de ser mulher e de ser homem, as escolhas na forma de se vestir, a identidade sexual, de gênero, social, cultural, a forma de encenar no mundo são parte da construção do mesmo sujeito, que devem ser reconhecidas como riqueza da diversidade existente em diferentes espaços educativos servindo como aprendizado de uma educação intercultural. É neste sentido, que defendemos a identidade livre e plural, sem amarras, desde que tenha como princípio a democracia e o respeito aos direitos e à justiça social.

Dubar (2006) traz a dualidade na definição das identidades, afirmando que a identidade para si e para o outro são ao mesmo tempo inseparáveis e controversas, o sujeito apenas sabe quem é pelo Outro.

"A divisão do Eu como expressão subjetiva da dualidade social aparece claramente através do mecanismo de identificação. Cada um é identificado por outrem, mas pode recusar essa identificação e se definir de outra forma. (...)." (DUBAR, 2006, p. 137).

É no diálogo no interior da constituição da identidade para o outro e para si que definimos o tipo de homem, de mulher, de profissional, que identificação étnica, religiosa, social buscamos e queremos ter.

$\mathrm{Na}$ busca por essa identificação, ressaltamos a busca da identidade étnica e racial, no contexto brasileiro, espaço marcado por atos de xenofobia, racismos agora não apenas de forma presencial no cotidiano escolar, mas, também, de forma virtual a partir das redes sociais, que impelem aos sujeitos tais atos com o falso respaldo do anonimato na rede.

A percepção acerca da identidade livre e plural que aqui se coloca pauta-se na autonomia para cada sujeito de viver as suas identidades, ou seja, poder ser de origem africana e gostar da culinária e tradições japonesas, sem que essa vivência hierarquize as duas culturas, numa perspectiva de que somos as nossas vivências, percepções, gostos e em um país diverso, com uma formação e construção a partir de diferentes culturas e povos imigrantes. 
O sujeito sempre será um encontro e diálogo entre e no interior dessa diversidade e sua identidade estará marcada por todos esses processos.

Para Flecha e Gómez (1995), a perspectiva comunicativa crítica, vertente existente no âmbito das Teorias Duais, afirma a necessidade de liberdade para viver diferentemente, pensando a democracia para todo mundo e nas vivências em qualquer território.

A liberdade que os autores trazem é a liberdade que aqui se defende no contexto das identidades, ou seja, poder ter a liberdade de escolher ser quem se deseja ser.

A perspectiva intercultural, se vivenciada na escola brasileira, como possibilidade, estará ancorada na ideia de liberdade de escolha no que se refere a identidade, mas ao mesmo tempo a defesa da unidade na diversidade, no sentido de que somos sim diferentes, mas, há elos que nos ligam e nos aproximam, como querer a mesma liberdade aos outros, pautar-se em princípios democráticos de participação e de manifestação de opiniões desde que a igualdade de diferenças seja o objetivo final de qualquer diálogo, vivência e aprendizagem.

A construção do conceito de identidade intercultural, ancorado nos pressupostos teóricos da unidade na diversidade, igualdade de diferenças e interculturalidade na possibilidade de múltiplas aprendizagens educativas em contextos educacionais, considerando-os como espaços múltiplos, diversos e que convivem neste espaço diferentes identidades, formas de ser, de estar e de se perceber sujeito do e no mundo, busca a construção de um processo de ensino e aprendizagem de qualidade para todos e todas.

\section{Construindo caminhos interculturais e dialógicos em diferentes contex- tos de aprendizagem}

$\mathrm{Na}$ busca de um processo educativo intercultural, dialógico e baseado na igualdade de diferenças, o movimento de olhar para as vivências do Outro é possibilitador de aprendizagens culturais, étnicas e raciais e de atuações à favor de transformações que podem superar fatores excludentes no processo.

A construção dialogada de sentidos, a partir das vivências, experiências, diálogos com vista ao entendimento e a validade do melhor argumento, igualdade de expor suas ideias, que possibilitam o processo de transformação, dentro da investigação social e educativa, estão espelhados na Metodologia Comunicativa (FLECHA, GÓMEZ e PUIGVERT, 2001; GÓMEZ e DÍEZ-PALOMAR, 2009).

Com o suporte bibliográfico e a análise crítica, dentro do quadro de referência da metodologia comunicativa, buscamos dialogar com as teorias e as vivências nos espaços educativos, especificamente em Angola, apresentando os fatores transformadores e excludentes deste processo. 
Neste contexto, dialogaremos com uma experiência decorrida em Luanda, capital de Angola nos anos de 2019 e primeiro semestre de 2020, intitulada "Projeto de Leitura e Escrita", uma iniciativa não-governamental, sem fins-lucrativos, realizada com meninas de 6 à 12 anos, que tem por objetivo trabalhar com as aprendizagens instrumentais de leitura e escrita a partir de temas geradores que são escolhidos a partir de um diálogo coletivo, em que todas as crianças opinam, apresentam suas ideias e seus desejos de conhecer um determinado tema que será desenvolvido a cada mês.

O planejamento dos temas à serem trabalhados no ano é realizado em conjunto e a cada mês a condução das atividades é pela educadora com apoio de meninas que se colocam voluntariamente para contribuir com a organização de uma atividade para o mês.

As habilidades instrumentais de leitura, escrita, compreensão, análise crítica, construção e desconstrução de conceitos e preconceitos são vivenciadas cotidianamente nos encontros realizados durante uma hora por semana.

No início do Projeto de Leitura e Escrita, era notário a dificuldade das crianças em olhar para a educadora que conduzia as atividades, pois, a percepção que possuem em seus imaginários sobre o que é a escola, como as crianças devem se comportar, se movimentar na escola estão carregadas de sentido e transpassaram para o espaço do projeto. A menina Fabiana (7 anos), nos primeiros encontros, apresentava uma dificuldade em olhar e dialogar com a educadora e suas colegas, no entanto, a partir da construção de atividades coletivas que possibilitaram o diálogo entre todas as meninas, com idades, saberes e experiências diversas, possibilitou a compreensão do espaço do projeto como espaço de diálogo e construção de conhecimentos de forma coletiva.

A construção dialogada e coletiva de conhecimentos possibilitou a construção de aprendizagens instrumentais e de aprendizagens que definiremos como interculturais, na medida em que as meninas de diferentes etnias, com diferentes línguas nacionais maternas, tradições e culturas, realizaram conjuntamente atividades trazendo as suas experiências, formas de pensar e de conceber o conhecimento.

Eu não conheço a cultura do outro se eu não perguntar como funciona, quais as regras, os códigos. Eu não conheço os impactos de uma baixa auto-estima se eu não ouvir, dialogar e reflectir sobre o que pensa, sente e como age o outro.

"A relação intercultural aparece como uma relação entre os diferentes em uma perspectiva de diálogo contínuo entre os indivíduos." (COELHO, 2011: p. 192).

A partir do tema "Sorriso", no grupo de meninas, dialogamos sobre o sonho, as possibilidades de ser feliz, pois o sorriso inspira emoções como a felicidade e a realização de sonhos. A participante Denise, de 6 anos, rapidamente, revela o seu sonho: "Estudar numa escola". 
A valorização dos processos de ensino e aprendizagem em espaços educacionais, como a escola, por exemplo, faz com que traga como um sonho, um desejo de felicidade a sua ida à escola.

Em outra atividade em que foi solicitado para que possam desenhar o dia mais feliz que tiveram em suas vidas e descrever os sentimentos deste dia, dentro da temática do mês que era "Carinho", trazendo algum episódio significativo, a Lurdes de 13 anos, desenha a ida à escola.

O diálogo, o respeito e o reconhecimento da capacidade de aprendizagem acadêmica e comunicativa de todas as crianças (...) faz com que cada um potencialize seus próprios avanços no processo de ensino e aprendizagem, o qual muitas vezes se encontra fragmentado (MELLO, BRAGA e GABASSA, 2012, p. 124).

A centralidade no conhecimento instrumental, atualmente, torna-se uma ferramenta que possibilita favorecer a máxima aprendizagem para todos, independente da sua condição social, o seu grupo étnico de referência, a sua forma de aprender e de viver no mundo.

As experiências educativas de crianças angolanas, destacadas, apresentam-se, dentro da vertente de educação dialógica e intercultural como fatores transformadores na medida em que estabalecem diálogos entre o a forma de ser e estar de si e do outro.

A ausência de um processo de escolarização formal, contínuo, organizado, considerando que no grupo de 13 meninas, apenas 3 estão matriculadas na escola formal, apresenta-se como um fator exclusor, pois impede que usufruam de seus direitos à educação, garantidos por lei. Tal aspecto, relaciona-se também com o fato de seus familiares serem migrantes, como podemos ver no diálogo com uma das participantes. A Márcia (10 anos) revela que gostaria de ter uma casa! A vida de idas e voltas de migrantes em Angola, é revelada em sua fala, trazendo o desejo de poder criar raízes em um local, vivenciar suas experiências em um espaço.

As migrações de diferentes povos para a capital do país, traz marcas na vida das crianças, na construção de laços, de afeto, entre outros aspectos. É notório a volta para o local de origem de algumas meninas que participaram no projeto, por decisões de vida, dificuldades na aquisição de um trabalho por parte de seus familiares, que acabam por regressar às províncias de origem.

As vivências das crianças de forma plural, construindo e reconstruindo suas identidades, suas visões de mundo, percepções de seus percursos, embora, possam se apresentar como fatores excludentes, ou seja, a mudança constante de local de moradia, por outro lado podem vir a se apresentar como possibilidades de vivências interculturais e dialógicas, pois nestes deslocamentos, 
acabam por conhecer crianças de grupos étnicos diferentes de seus grupos de origem, vivenciando e conhecendo outras culturas.

Reconhecer a pluralidade, a diversidade e as diferenças na escola é o passo inicial para compreender as possibilidades de transformação desse espaço em uma escola que prioriza a aprendizagem de todas as crianças (MELLO, BRAGA e GABASSA, 2012) e adolescentes, escola em que o professor é valorizado assim como o seu trabalho cotidiano, seu empenho e o seu "não-saber", entendendo que todos e todas têm o direito à aprender.

\section{Considerações finais}

A partir das múltiplas experiências vivenciadas no projeto, nota-se a possibilidade da vivência da identidade intercultural, ou seja, a criança busca no grupo se sentir parte desse universo e busca construir dialogicamente significados, conhecimentos e história. Neste sentido, no contexto brasileiro, a identificação da criança negra na escola brasileira com seus pares e com os traços positivos que as culturas de origem africanas trazem, podem revelar-se como uma oportunidade de viver a igualdade de diferenças.

Ao voltarmos a nossa análise à escola pública brasileira, onde grande parte das crianças negras estão inseridas, mas não se vêem valorizadas no grupo e não encontram o ponto de conexão intersubjetiva entre o que elas são, a sua constituição identitária, e o que esperam que elas sejam, dentro do contexto da identidade de origem européia, classe média, etc., é possível percebermos a importância do conhecimento da realidade educativa angolana, as vivências múltiplas em espaços que possibilitam a valorização das suas identidades, escolhas, formas de ser, de estar, de vestir e se pentear e como esse conhecimento pode estabelecer um diálogo com o que podemos construir nos espaços educativos.

\section{Referências}

AUBERT, Adriana; GARCIA, Carme e RACIONERO, Sandra. El aprendizaje dialógico. Cultura y Educación, 2009, n 21(1), p. 129-139.

BOTTON, Lena de. Igualdad de diferencias desde la mujer árabe. In: TOURAINE, Alain. et al. Conocimiento e identidad: voces de grupos culturales en la investigación social. Barcelona: El Roure Editorial, 2004.

COELHO, Marciele Nazaré. Lembranças de Angola e vivências no Brasil: educação, trabalho e diversidades étnica e raciais de mulheres angolanas. Holambra, SP: Editora Setembro, 2011. 
COELHO, Marciele Nazaré; CONSTANTINO, Francisca de Lima e MOREIRA, Raquel. Diálogo, igualdade e diversidade: uma tríade para o respeito às diferenças na escola. XVI ENDIPE - Encontro Nacional de Didática e Práticas de Ensino. UNICAMP, Campinas: Junqueira \& Marin Editores, p. 1945-1956, 2012. Disponível em: http:/ /www. infoteca.inf.br/endipe/smarty/templates/arquivos_template/upload_arquivos/acervo/ docs/2012d.pdf. Acesso em: 18 out. 2020.

DUBAR, Claude. A socialização: construção das identidades sociais e profissionais. Trad. Andréia Stahel M. da Silva. São Paulo: Martins Fontes, 2006.

ELBOJ, Carmen Saso et. al. Comunidades de aprendizaje: transformar la educación. Espanha: Graó, 2002.

FLECHA, Ramón; GÓMEZ, Jesús. Racismo; no, gracias. Ni moderno, ni postmoderno. Barcelona: El Roure Editorial, 1995.

FLECHA, Ramón; TORTAJADA, Iolanda. Desafios e saídas educativas na entrada do século. In: IMBERNÓN, Francisco. A educação no século XXI: os desafios do futuro imediato. Porto Alegre: Artmed, 2000. p. 195-205. Disponível em: https://statics-submarino.b2w.io/sherlock/books/firstChapter/180961.pdf.

FLECHA, Ramón; GÓMEZ, Jesús. e PUIGVERT, Lídia. Teoria sociológica contemporânea. Barcelona, Paidós, 2001.

FREIRE, Paulo. A pedagogia do Oprimido. $17^{\mathrm{a}}$ ed. Rio de Janeiro: Paz e Terra, 1987.

FREIRE, Paulo. Pedagogia da Esperança. 13ª ed. Rio de Janeiro: Paz e Terra, 2006.

GÓMEZ, Ailton Gonzáles; DÍEZ-PALOMAR, Javier. Metodología comunicativa crítica: transformaciones y câmbios en el XXI. Revista Electrónica Teoría de la Educación. Educación y cultura en la Sociedade de la Información. Vol. 10, n 3, noviembre, 2009. p. 105 -118. Disponível em: https://www.researchgate.net/publication/42377354_Metodologia_comunicativa_critica_transformaciones_y_cambios_en_el_S_XXI.

GRIMSON, Alejandro. Interculturalidad y comunicación. Colombia: Grupo Editorial Norma, 2001.

LIMA CONSTANTINO, Francisca; COELHO, Marciele Nazaré. Contributions of Brazilian educational policies: possibilities for dialogue and valuing ethnic and racial diversity in the school context. International Journal of Roma Studies, [S.1.], p. 41-63, mar. 2020. ISSN 2462-425X. Available at: <https://hipatiapress.com/hpjournals/index.php/ ijrs/article/view/5120>. Date accessed: 24 july 2020. doi:http://dx.doi.org/10.17583/ ijrs.2020.5120.

LÓPEZ, Luis Enrique. Interculturalidad, educación y política en América Latina: perspectivas desde Sur pistas para una investigación comprometida y dialogal. In: (edit.)

Interculturalidad, educación y ciudadanía: perspectivas latino-americanas. Bolívia: FUNPROEIB Andes; Plural Editores, 2009. p. 129-218.

MARÍN, José. Eurocentrismo, el racismo y interculturalidad en el contexto de la globalización. Revista de Educação Pública, v. 26, n. 62/2, maio/ago. 2017. p. 477-491. 
MELLO, Roseli Rodrigues de; BRAGA, Fabiana Marine e GABASSA, Vanessa. Comunidades de aprendizagem: outra escola é possível. São Carlos: EdUFSCar, 2012.

MOYA, Ruth. La interculturalidad para todos en América Latina. In: LÓPEZ, Luis Enrique. Interculturalidad, educación y ciudadanía: perspectivas latino-americanas. Bolívia: FUNPROEIB Andes; Plural Editores, 2009. p. 21-56. Disponível em: http:// bvirtual.proeibandes.org/bvirtual/docs/inter_edu_cuidadania.pdf. Acesso em 20 de set. 2020.

MOYA, Ruth.; LÓPEZ, Luis Enrique; VALIENTE, Teresa. (coord.). Interculturalidad y Educación: dialogo para la democracia en América Latina. Coleção Pueblos Indígenas y Educación. Julio - Diciembre. No 45-46. Número Especial, 1999. (Presentación). Disponível em: http://digitalrepository.unm.edu/cgi/viewcontent.cgi?article=1242\&context=abya_yala Acesso em: 24 set. 2020.

PAULA, Eunice Dias de. A interculturalidade no cotidiano de uma escola indígena. Cadernos Cedes, ano XIX, no 49, Dezembro. p. 76-91, 1999. Disponível em: http:/ /www. scielo.br/pdf/\%0D/ccedes/v19n49/a07v1949.pdf. Acesso em: 11 out. 2020.

PLEYERS, Geoffrey. Altermundialismo y multiculturalismo: algunas pistas de reflexión. In: TOURAINE, A. et alli. Conocimiento e identidad: voces de grupos culturales en la investigación social. Barcelona: El Roure Editorial, 2004.

SPEISER, S. El para qué de la interculturalid en la educación. In: Moya, Ruty, López, L. E.; Valiente, T. (coord.). Interculturalidad y Educación: dialogo para la democracia en América Latina. Coleção Pueblos Indígenas y Educación. Julio - Diciembre. $\mathrm{N}^{\circ}$ 45-46. Número Especial, 1999. Disponível em: http://digitalrepository.unm.edu/cgi/ viewcontent.cgi?article $=1242 \&$ context $=$ abya_yala. Acesso em: 12 set. 2020 . 